\title{
Implementasi Sistem Pengaturan Suhu Ruang Server Menggunakan Sensor DHT11 dan Sensor PIR Berbasis Mikrokontroler
}

\author{
Gunawan $^{1}$, Titin Fatimah ${ }^{2}$ \\ ${ }^{1,2}$ Program Studi Teknik Informatika, Universitas Budi Luhur \\ email: awan3rdchild@gmail.com ${ }^{1}$, titin.fatimah@ @udiluhur.ac.id ${ }^{2}$
}

(Received: 28 Mei 2020/ Accepted: 8 Juni 2020 / Published Online: 20 Juni 2020)

\begin{abstract}
Abstrak
Sistem pengaturan suhu merupakan sistem yang sangat penting pada ruang server. Ruang server yang memiliki suhu dan kelembapan yang tinggi akan mempengaruhi kinerja dari perangkat jaringan yang mengakibatkan perangkat jaringan akan mudah rusak. Kemudian jika lampu pada ruang server menyala secara terus menerus mengakibatkan bertambahnya suhu ruangan dan pemborosan daya listrik yang berdampak pada peningkatan pembayaran tagihan listrik. Maka dari itu diperlukan sistem yang dapat melindungi devices yang tersimpan di dalam ruang server serta dapat mengelola ruang server. Mengatasi permasalahan tersebut dikembangkan sebuah alat yang bertujuan untuk dapat mengontrol suhu dan lampu pada ruang server secara otomatis serta melakukan monitoring suhu dan kelembapan. Metode pengembangan sistem ini menggunakan prototype yang dimulai dengan mewawancarai secara langsung staf IT, membuat dan memperbaiki prototype dan staf IT menguji coba prototype, serta metode black box digunakan untuk mengevaluasi sistem ini. Hasil pengujian didapatkan bahwa sensor DHT11 dapat mendeteksi suhu dan kelembapan, IR Transmitter dapat mengontrol Air Conditioner (AC), Sensor Passive InfraRed dapat mendeteksi pergerakan dan mikrokontroler NodeMCU dapat mengendalikan alat serta mengirimkan dan menyimpan data suhu dan kelembapan ke dalam database. Kesimpulannya adalah sistem dapat mengontrol suhu dan monitoring pada ruang server dengan baik dan dapat mengontrol lampu secara otomatis.
\end{abstract}

Kata kunci : Mikrokontroler, Monitoring Suhu, Pengaturan Suhu Otomatis

\begin{abstract}
Temperature setting system is a very important system in the server room. Server room that has a high temperature, and humidity will be influencing the performance of the network device that causes a network device broke easily. And then, if the light in server room is continuously lit, it will cause the increase of room's temperature and waste electricity that impact on intensify electricity bill. Therefore, it needs a system that can protect devices, which saved in the server room, also can manage the server room. For resolving those problems, developed a tool that aims to control the temperature and the light in server room automatically monitoring the temperature and humidity. This system development method uses a prototype method that starts with interviewing IT staff directly, make and repair the prototype and IT staff, test and trying the prototype. Testing was done by using black box method testing. The test result obtained that DHT11 sensor can detect the temperature and humidity, IR Transmitter can control the Air Conditioner (AC), Passive InfraRed sensor can detect the movement and NodeMCU microcontroller can manage the tool, also send and save the temperature data and humidity in the database. The conclusion is system can control the temperature and monitoring the server room well and can control the light automatically.
\end{abstract}

Keywords: Microcontroller, Temperature Monitoring, Automatic Temperature Setting

\section{PENDAHULUAN}

Seiring dengan perkembangan teknologi dan ilmu pengetahuan khususnya pada bidang elektronika dan juga bidang telekomunikasi, membuat manusia selalu berusaha untuk memanfaatkan teknologi untuk mempermudah kegiatan dalam kehidupan sehari-hari. Salah 
satunya yaitu dalam pengaturan suhu AC (Air Conditioner) pada ruang server. Selama ini yang kebanyakan terjadi pengaturan suhu AC hanya menggunakan remote control (Khoswanto et al., 2003). Keadaan ini akan sangat merepotkan jika setiap kali ada perubahan maka setiap kali itu pula temperature harus diset ulang melalui remote control (Fauzi \& Mukhtar, 2016). Oleh karena itu dibutuhkan suatu inovasi baru agar AC dapat dijalankan secara otomatis dengan bantuan mikrokontroler NodeMCU dan sensor DHT11. Mikrokontroler yaitu sebuah perangkat komputasi kecil yang terdiri dari sebuah IC dengan microprocessor di dalamnya yang dapat mengatur input dan output dari alat lain (Wijanarko \& Hasanah, 2017). Mikrokontroler NodeMCU mempunyai berbagai fitur kapabilitas akses terhadap wifi dan chip komunikasi USB to serial (Iqbal et al., 2019). Selain itu suhu ruangan juga dapat dimonitoring dan dikendalikan dari jarak jauh yaitu berbasis Internet of Things (IoT) (Periyaldi et al., 2018). Pada sistem Internet of Things (IoT) dalam pengiriman data antar perangkat menggunakan jaringan internet (Partamayasa et al., 2019). Banyak permasalahan selama ini seorang staf IT harus berada pada ruang server jika ingin mengatur atau memonitoring suhu ruangan server. Monitoring suhu dalam rentang waktu tertentu adalah salah satu hal yang cukup penting untuk dilakukan (Permana \& Herawati, 2018). Mengingat suhu merupakan salah satu hal utama yang sangat berpengaruh terhadap kondisi perangkat di ruang server (Suherman et al., 2015) Dimana pada perangkat server perlu dijaganya kestabilan suhunya. Karena ketika suhu di ruang server naik akan menyebabkan kerusakan pada perangkat jaringan dan umur perangkat jaringan tidak bertahan lama (Abdullah \& Wibowo, 2014).

Selain itu ruang server yang masih menggunakan saklar manual, staf IT terkadang lupa untuk mematikan lampu yang menyebabkan lampu akan menyala secara terus menerus. Apabila lampu menyala secara terus menerus maka berakibat bertambahnya suhu ruangan, mengurangi umur/masa lampu dan pemborosan daya listrik (Djaeng \& Astutik, 2017; Prihatmoko, 2016). Ini tentunya juga dapat menimbulkan kerugian berupa peningkatan pembayaran pada tagihan listrik (Lukman et al., 2018). Dengan permasalah tersebut maka dibutuhkan sebuah alat yang dapat bekerja secara otomatis dalam pengontrolan sebuah lampu. Pada sistem ini digunakanlah sensor PIR sebagai pendeteksi pergerakan manusia didalam ruangan. Sensor PIR (Passive InfraRed) bekerja dengan cara mendeteksi adanya pancaran sinar infra merah (Siswanto et al., 2017).

Pada penelitian yang dilakukan oleh Partamayasa et al., (2019), mereka menggunakan mikrokontroler Arduino mega, sensor DHT11 dan IR Transmitter untuk mengendalikan AC. Sensor mengirimkan data dan diproses oleh mikrokontroler kemudian memberikan perintah ke IR Transmitter untuk menaikan dan menurunkan suhu pada AC. Data suhu dan kelembapan dari sensor DHT11 selanjutnya disimpan kedalam database dan kemudian ditampilkan kedalam website. Sedangkan penelitian yang dilakukan oleh (Wijaya et al., 2018), perancangan sistem pemantauan suhu dan kelembapan alat incubator dirancang agar bekerja secara otomatis dan dapat dipantau dari jarak cukup jauh dengan menggunakan akses internet. Penelitian ini menggunakan arduino mini pro sebagai mikrokontroler dan modul wireless ESP-8266 sebagai penghubung ke wifi. Sistem komunikasi alat monitoring suhu dan kelembapan pada alat Incubator Baby terintegrasi dengan Internet of Things dengan menggunakan ThingSpeak sebagai web server penyimpanan data. Beberapa penelitian tersebut diantaranya masih menggunakan mikrokontroler arduino yang masih memerlukan modul tambahan lagi untuk terhubung ke wifi, oleh karena itu pada penelitian ini menggunakan mikrokontroler NodeMCU yang didalamnya sudah terdapat modul wifi.

Tujuan penggunaan sistem ini di dalam ruang server yaitu untuk mengontrol suhu dan lampu pada ruang server secara otomatis serta melakukan monitoring suhu dan kelembapan. Alat akan memberikan perintah kepada AC menaikkan atau menurunkan suhu ruangan secara otomatis sesuai dengan suhu optimal kemudian data suhu dan kelembapan akan disimpan ke 
database dan ditampilkan ke website. Dengan adanya sistem ini maka suhu ruangan akan terjaga, pengeluaran suhu AC dapat bekerja seoptimal mungkin (Aryandhi \& Talakua, 2013), pengontrolan lebih efektif dan efisien (Supriyanto et al., 2017) dan pemantauan suhu dan kelembapan bisa dilakukan dimana saja (Mulyono \& Haviana, 2018). Alat tersebut juga akan mengontrol lampu di ruang secara otomatis menyala ketika mendeteksi pergerakan manusia dan akan mati ketika tidak ada pergerakan.

\section{METODE}

Metode dalam merancang dan membuat sistem pengaturan suhu ruang server menggunakan sensor DHT11 dan sensor PIR berbasis mikrokontroler ini, metode yang digunakan yaitu prototype. Prototype adalah suatu model/metode dalam pengembangan sistem yang menggunakan pendekatan untuk membuat sesuatu aplikasi dengan cepat dan bertahap sehingga dapat di evaluasi oleh pemakai (Suherman et al., 2015). Pada metode prototype terdapat beberapa tahapan meliputi : yang pertama yaitu mewawancarai secara langsung Staf IT. Pada tahap ini peneliti meminta data dan informasi mengenai permasalahan sistem yang berjalan pada ruang server dan mencari studi literatur sebagai penunjang pada sistem. Langkah kedua merancang dan membuat prototype. Tahap ini dilakukan perancangan dan pembuatan prototype sistem. Prototype yang dibuat disesuaikan dengan kebutuhan sistem yang telah didefinisikan sebelumnya dari keluhan staf IT. Langkah ketiga yaitu uji coba. Pada tahap ini staf IT menguji coba sistem yang sudah dibuat dan dibangun kemudian dilakukan evaluasi kekurangan-kekurangan dari kebutuhan staf IT. Pada tahap ini digunakan model black box untuk melakukan pengujian pada sistem ini. Peneliti kemudian kembali mendengarkan keluhan dari staf IT untuk memperbaiki sistem yang telah dibuat pada sebelumnya.

Pada tahap perancangan sistem dijelaskan tentang implementasi sistem pengaturan suhu ruang server menggunakan sensor DHT11 dan sensor PIR berbasis mikrokontroler, perancangan pada penelitian ini dibagi menjadi dua proses yaitu meliputi proses perancangan perangkat keras (hardware) dan perancangan perangkat lunak (software). Hasil perancangan tersebut dapat dilihat pada gambar 1 dibawah ini.

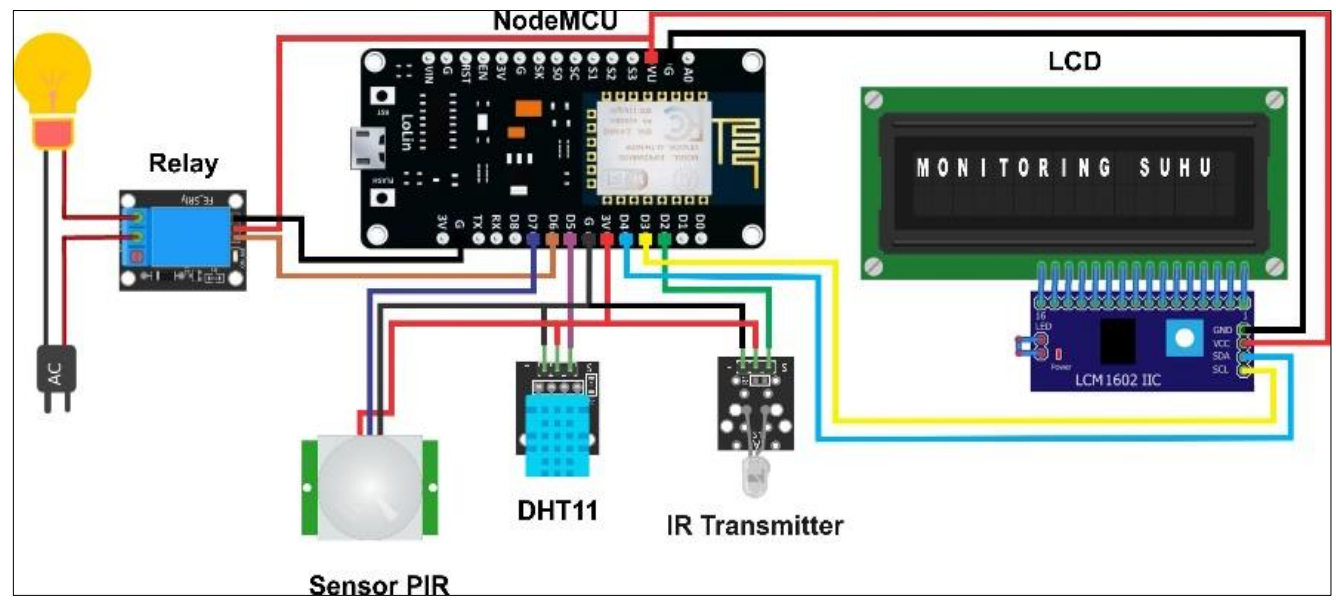

Gambar 1. Perancangan Perangkat Keras (Hardware)

Pada gambar 1 merupakan perancangan perangkat keras (hardware) pada penelitian ini. Sebagai kontrol utama yaitu terdiri dari mikrokontroler NodeMCU, sensor DHT11, sensor PIR, IR Transmitter, Relay dan LCD 16x2 dengan modul IC2. Pada gambar 2 merupakan perancangan perangkat lunak dari sistem ini. Cara kerja sistem ini yaitu yang pertama mikrokontroler melakukan initialisasi alat, kemudian pada bagian setup mikrokontroler melakukan koneksi ke wifi, jika alat terkoneksi selanjutnya ke bagian loop dan apabila gagal, 
maka akan melakukan proses automasi lampu dan pengaturan suhu. Pada bagian loop mikrokontroler melakukan koneksi ke MQTT, jika terkoneksi maka selanjutnya melakukan proses subscribe dari MQTT, kemudian melakukan proses automasi lampu dan pengaturan suhu dilanjutkan mengirimkan data humidity, temperature dan temperature optimal ke database.

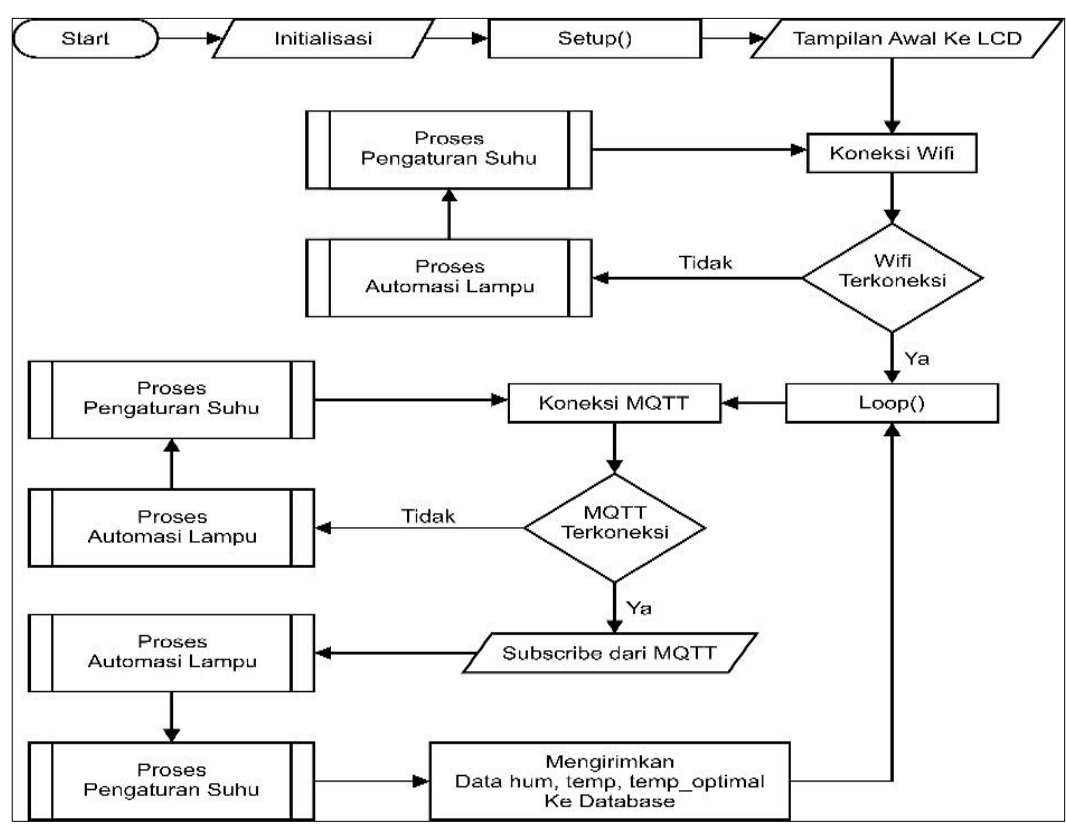

Gambar 2. Perancangan Perangkat Lunak (Software)

\section{HASIL DAN PEMBAHASAN}

\section{Hasil Penelitian}

Berikut ini adalah hasil penelitian dari sistem pengaturan suhu ruang server menggunakan sensor DHT11 dan sensor PIR berbasis mikrokontroler yang telah dibuat. Hasil penelitian ini dapat dilihat atau disajikan pada gambar-dibawah ini.

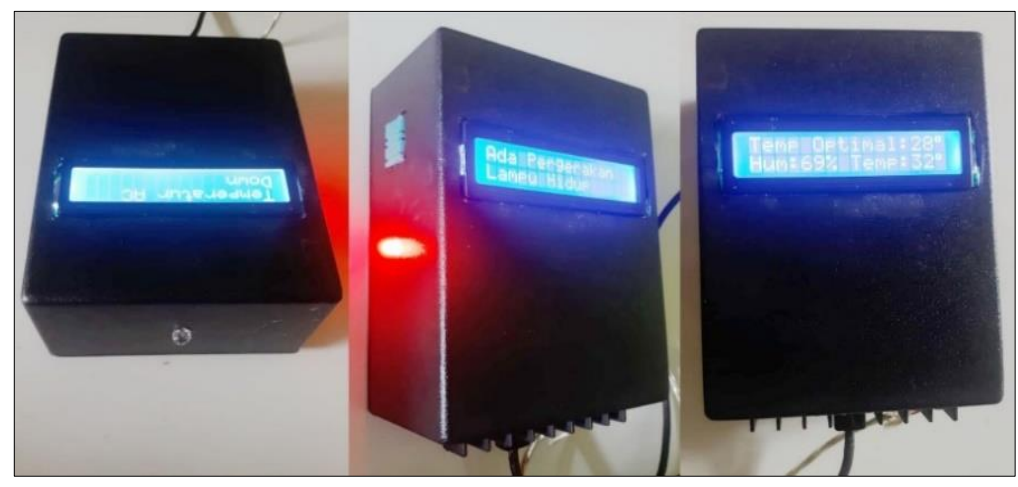

Gambar 3. Rangkaian Hardware

Berdasarkan gambar 3 rangkaian hardware mikrokontroler diletakkan didalam box hitam, Modul LCD ditempatkan di depan, sensor DHT11 diletakkan di bagian samping, sensor PIR dihubungkan dengan kabel ke soket dan IR Transmitter diletakkan pada bagian atas box. 


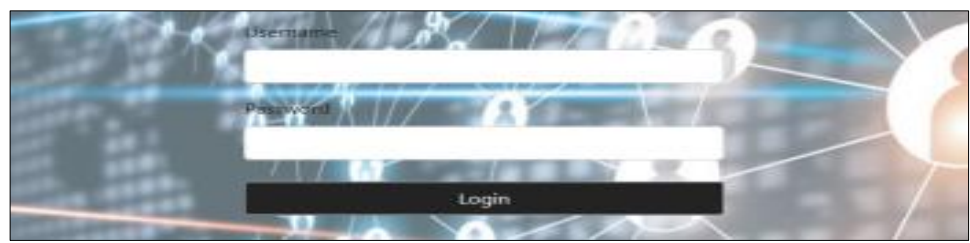

Gambar 4. Menu Login

Tampilan menu login akan muncul ketika pertama kali program ini dijalankan. User diminta untuk login terlebih dahulu dengan memasukan username dan password. Terdapat 2 level user pada program ini, yaitu level admin dan staf (lihat gambar 4). Pada gambar 5 adalah tampilan dari menu home admin yang merupakan sebuah menu awal ketika pengguna sudah berhasil login kedalam sistem dengan level admin. Pada halaman home admin terdapat beberapa menu yaitu menu home, data sensor, control room, setting server dan keluar. Pada bagian konten terdapat data terakhir humidity, temperature dan temperature optimal, grafik dan terdapat tampilan tabel 10 data terakhir yang tersimpan pada database.
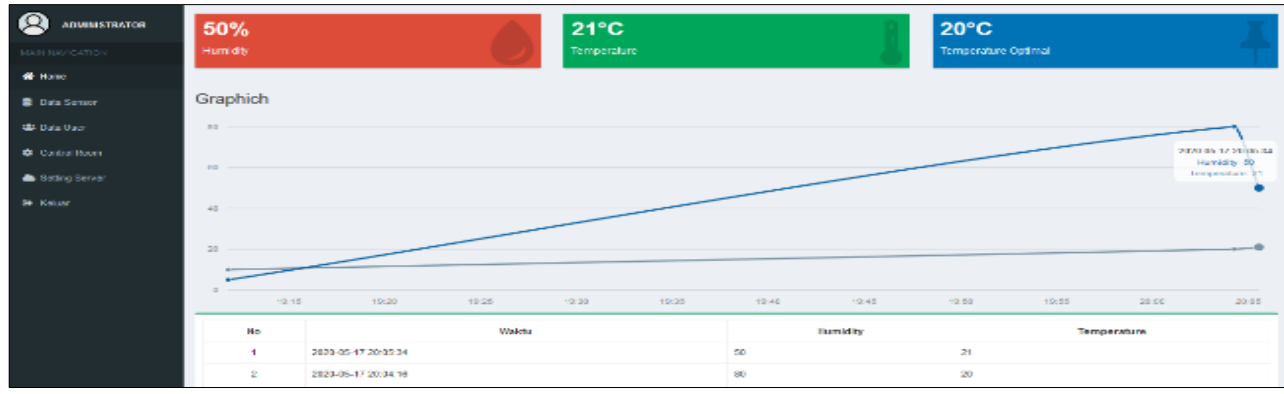

Gambar 5. Menu Home Admin

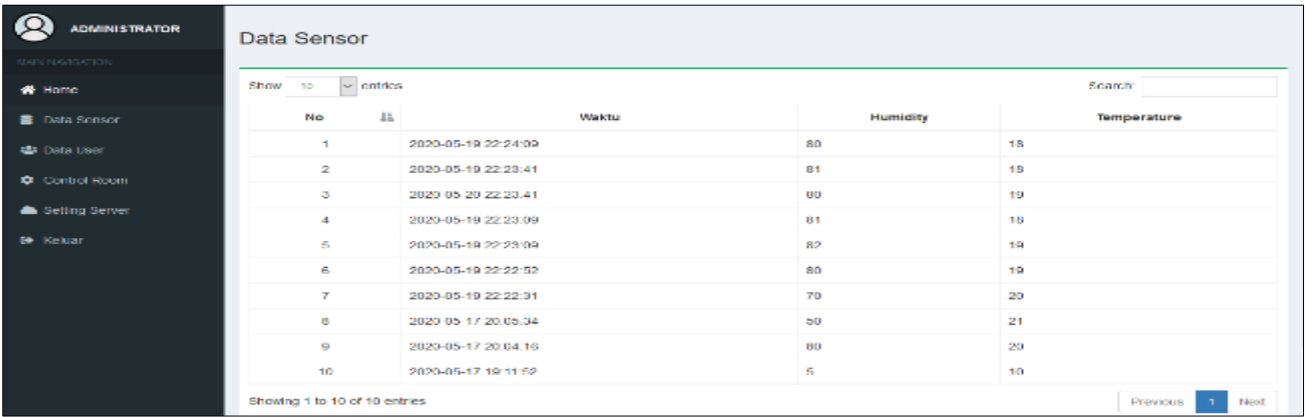

Gambar 6. Menu Admin Data Sensor

Pada gambar 6 adalah halaman menu admin data sensor yang mana akan menampilkan semua data waktu, humidity dan temperature yang tersimpan didalam database. Dalam halaman ini terdapat juga kolom search yang berguna untuk melakukan pencarian data, show yang berfungsi untuk mengatur banyak data yang akan ditampilkan dan pagination yang berguna untuk menampilkan data selanjutnya.
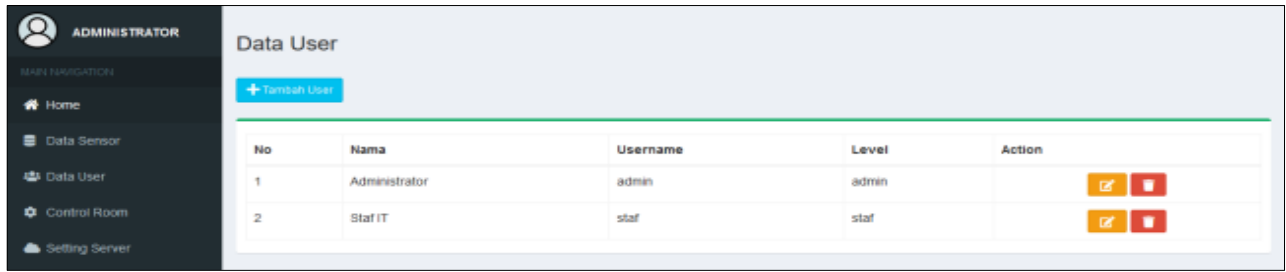

Gambar 7. Menu Admin Data User 
Pada gambar 7 adalah halaman menu admin data user yang akan menampilkan informasi tentang semua data user yang tersimpan di database. Terdapat juga tombol tambah user untuk beralih ke form tambah user, tombol edit untuk beralih ke form edit user dan tombol delete untuk menghapus user. Selanjutnya, Pada gambar 8 adalah halaman menu admin control room yang akan menampilkan status temperature optimal dari sistem ini. Terdapat tombol edit untuk beralih ke form edit temperature optimal yang berguna untuk merubah nilai temperature optimal.

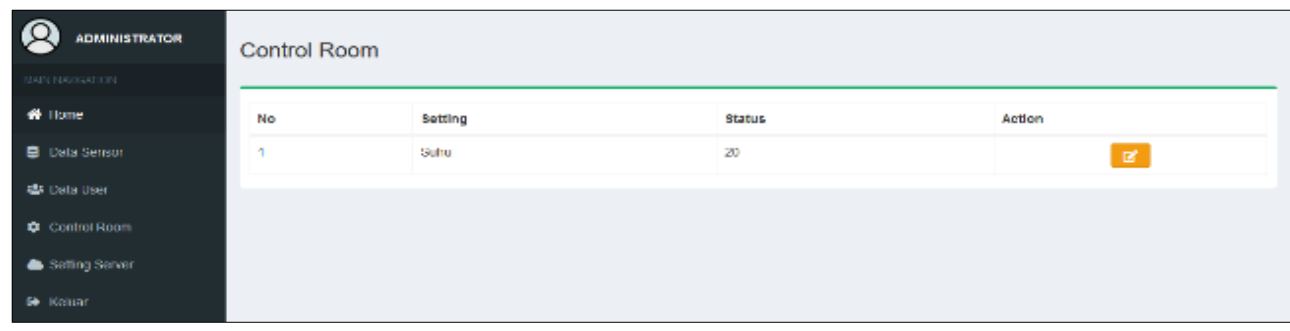

Gambar 8. Menu Admin Control Room

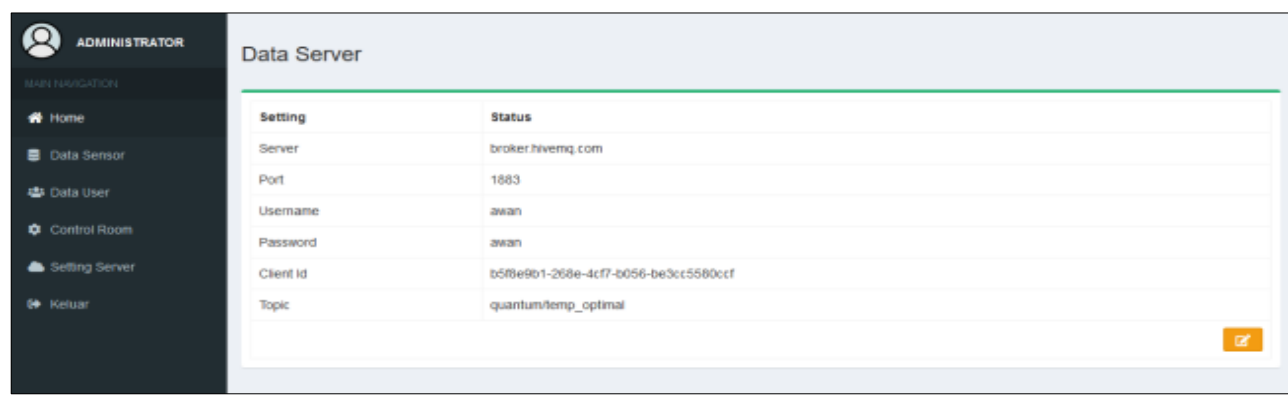

Gambar 9. Menu Admin Setting Server

Pada gambar 9 adalah halaman menu admin setting server yang akan menampilkan data server MQTT dari sistem ini. Terdapat tombol edit untuk beralih ke form edit setting server yang berguna untuk merubah data tentang server yang digunakan.

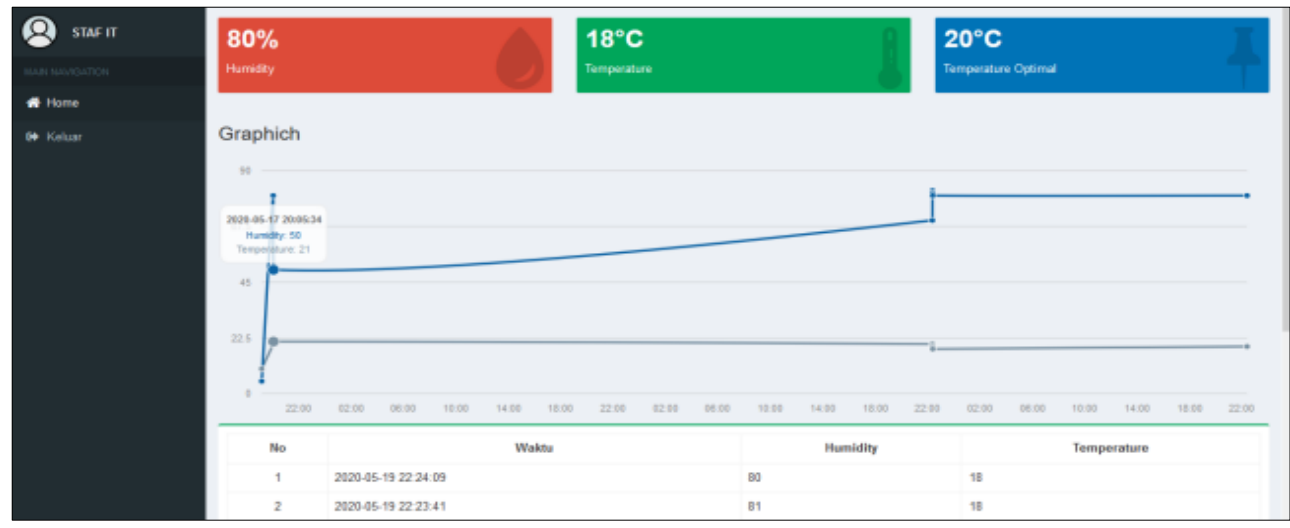

Gambar 10. Menu Home Staf

Pada gambar 10 adalah menu home staf yang merupakan sebuah menu awal ketika pengguna sudah berhasil login kedalam sistem dengan level staf. Pada halaman home admin terdapat 2 menu yaitu menu home dan keluar. Pada bagian konten terdapat data terakhir humidity, temperature dan temperature optimal, grafik dan terdapat tampilan tabel data terakhir yang tersimpan pada database. 


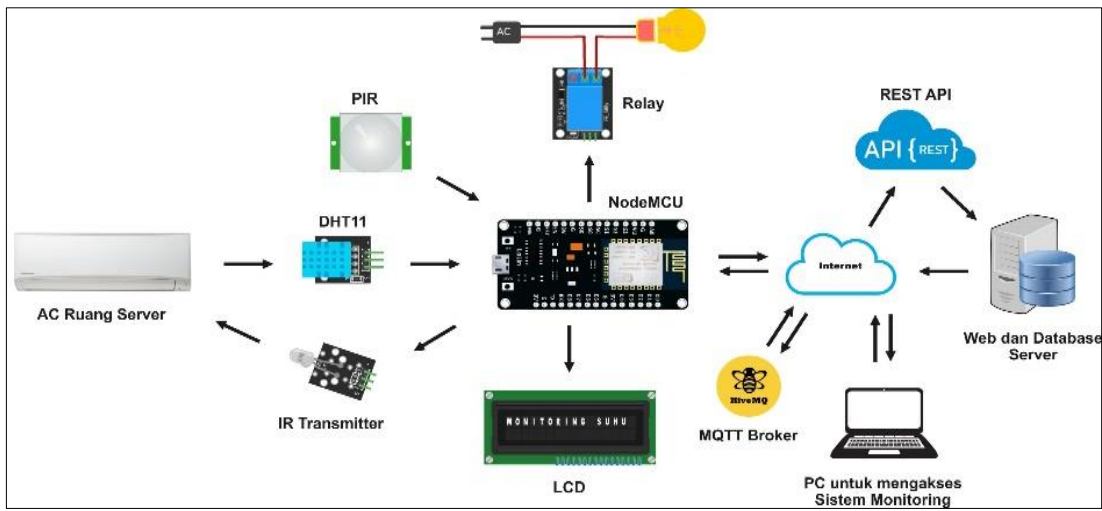

Gambar 11. Gambaran Sistem Secara Umum

Proses alur penerimaan dan pengiriman data dari masing-masing alat pada sistem ini. Dimulai dari pendeteksian sensor, kemudian pemrosesan data, menghasilkan keluaran untuk mengontrol alat, hingga menampilkan data pada website (lihat gambar 11).

\section{Pengujian}

Tahap ini bertujuan untuk mengetahui kelayakan sistem yang di kembangkan oleh peneliti serta mengetahui kesalahan yang ada pada sistem dan memperbaikinya. Berikut ini adalah beberapa pengujian yang dilakukan, pengujian tersebut dapat dilihat pada tabel pengujian black box. Pengujian Black Box IR Transmitter berfungsi untuk mengetahui seberapa jauh jarak IR Transmitter dalam mengirimkan data. Hasilnya pengujian dapat dilihat pada tabel 1 .

Tabel 1. Pengujian Black Box IR Transmitter

\begin{tabular}{ccccc}
\hline No & Kasus Uji & Jarak Uji & Hasil Uji Yang Diharapkan & Hasil \\
\hline 1 & & $<480 \mathrm{~cm}$ & Dapat mengirimkan data & $\checkmark$ \\
2 & IR Transmitter & $>480 \mathrm{~cm}$ & Tidak dapat mengirimkan data & $\checkmark$
\end{tabular}

Keterangan : Dari pengujian diatas diketahui bahwa IR Transmitter tidak dapat mengirimkan data lebih dari jarak $480 \mathrm{~cm}$.

Pengujian Black Box Sensor PIR berfungsi untuk mengetahui seberapa jauh sensor PIR dalam mendeteksi pergerakan manusia. Hasilnya pengujian dapat dilihat pada tabel 2 dibawah ini.

Tabel 2. Pengujian Black Box Sensor PIR

\begin{tabular}{ccccc}
\hline No & Kasus Uji & Jarak Uji & Hasil Uji Yang Diharapkan & Hasil \\
\hline 1 & & $<670 \mathrm{~cm}$ & Mendeteksi pergerakan & $\checkmark$ \\
2 & Sensor PIR & $>670 \mathrm{~cm}$ & Tidak mendeteksi pergerakan & $\checkmark$ \\
\hline
\end{tabular}

Keterangan: Hasil uji coba sensor PIR diatas mendapatkan hasil bahwa sensor dapat mendeteksi pergerakan diatas jarak $670 \mathrm{~cm}$.

Pengujian Black Box Sensor DHT11 ini bertujuan untuk mengetahui sensitivitas sensor dalam membaca suhu dan kelembapan. Pengujian sensor DHT11 dapat dilihat pada tabel 3. Pengujian Black Box Mikrokontroler ini bertujuan untuk menguji kerja dari mikrokontroler. Hasil pengujian tersebut terlihat pada tabel 4. 
Tabel 3. Pengujian Black Box Sensor DHT11

\begin{tabular}{ccccc}
\hline No & Kasus Uji & $\begin{array}{c}\text { Kondisi } \\
\text { Pengujian }\end{array}$ & Hasil Uji Yang Diharapkan & Hasil \\
\hline 1 & Sensor & $\begin{array}{c}\text { Didekatkan } \\
\text { dengan solder } \\
\text { Diletakkan diruang } \\
\text { berAC }\end{array}$ & $\begin{array}{c}\text { Output suhu bernilai tinggi, output } \\
\text { kelembaban bernilai rendah } \\
\text { Output temperature bernilai rendah, } \\
\text { output kelembaban bernilai tinggi }\end{array}$ & $\checkmark$ \\
\hline
\end{tabular}

Keterangan : Dari pengujian diatas diketahui bahwa sensor DHT 11 jika didekatkan degan solder maka suhu bernilai tinggi dan kelembaban rendah apabila ditelakkan diruang berAC suhu bernilai rendah dan kelembaban tinggi.

Tabel 4. Pengujian Black Box Mikrokontroler

\begin{tabular}{|c|c|c|c|c|}
\hline No & Kasus Uji & Kondisi Pengujian & Hasil Uji Yang Diharapkan & Hasil \\
\hline 1 & & $\begin{array}{l}\text { Terkoneksi dengan } \\
\text { wifi }\end{array}$ & $\begin{array}{l}\text { Menampilkan keterangan } \\
\text { "Wifi Terhubung" }\end{array}$ & $\checkmark$ \\
\hline 2 & & $\begin{array}{l}\text { Tidak terkoneksi } \\
\text { dengan wifi }\end{array}$ & $\begin{array}{l}\text { Menampilkan keterangan } \\
\text { "Wifi Menghubungkan" }\end{array}$ & $\checkmark$ \\
\hline 3 & & $\begin{array}{l}\text { Terkoneksi dengan } \\
\text { server MQTT }\end{array}$ & $\begin{array}{l}\text { Menampilkan keterangan } \\
\text { "MQTT Terhubung" }\end{array}$ & $\checkmark$ \\
\hline 4 & Mikrokontroler & $\begin{array}{l}\text { Tidak terkoneksi } \\
\text { dengan server } \\
\text { MQTT }\end{array}$ & $\begin{array}{l}\text { Menampilkan keterangan } \\
\text { "MQTT Menghubungkan" }\end{array}$ & $\checkmark$ \\
\hline 5 & & $\begin{array}{c}\text { Menerima pesan dari } \\
\text { MQTT }\end{array}$ & $\begin{array}{c}\text { Menampilkan keterangan } \\
\text { "Perbaruhi Temperature } \\
\text { Optimal" }\end{array}$ & $\checkmark$ \\
\hline 6 & & $\begin{array}{c}\text { Berhasil } \\
\text { mengirimkan data ke } \\
\text { database }\end{array}$ & $\begin{array}{l}\text { Menampilkan keterangan } \\
\text { "Berhasil Mengirim Data" }\end{array}$ & $\checkmark$ \\
\hline 7 & & $\begin{array}{l}\text { Gagal mengirimkan } \\
\text { data ke database }\end{array}$ & $\begin{array}{l}\text { Menampilkan keterangan } \\
\text { "Gagal Mengirim Data" }\end{array}$ & $\checkmark$ \\
\hline
\end{tabular}

Keterangan :

LCD menampilkan tulisan wifi terhubung ketika mikrokontroler NodeMCU terkoneksi ke wifi, apabila tidak terkoneksi LCD akan menampilkan tulisan wifi menghubungkan.

LCD menampilkan tulisan MQTT terhubung ketika mikrokontroler NodeMCU terkoneksi ke server MQTT, apabila tidak terkoneksi LCD akan menampilkan tulisan MQTT menghubungkan.

LCD menampilkan tulisan perbaruhi temperature optimal apabila mikrokontroler NodeMCU mendapatkan nilai temperature optimal dari sistem web.

LCD akan menampilkan tulisan berhasil mengirim data apabila mikrokontroler berhasil mengirimkan data suhu dan kelembapan ke database, jika gagal LCD menampilkan tulisan gagal mengirim data.

\section{Pembahasan}

Berdasakan dari hasil di atas, pengimplementasian sistem pengaturan suhu ruang server menggunakan sensor DHT11 dan sensor PIR berbasis mikrokontroler. Dalam pengembangan 
sistem ini, menerapkan metode prototype di mana memiliki tahapan - tahapan, diantaranya : Mewawancarai secara langsung staf IT, Membuat dan memperbaiki prototype, Staf IT menguji coba prototype. Tahap - tahap ini berguna untuk menentukan apa saja yang di butuhkan dalam mengembangkan sistem dengan cara mewawancarai langsung ke ke staf IT. Selanjutnya merancang sistem dan merakit sistem serta merancang program dan yang terakhir yaitu dilanjutkan dengan pengujian tingkat kelayakan dari sistem dan memperbaikinya. Dari hasil pembuatan sistem diatas mendapatkan hasil bahwa sistem dapat mengontrol suhu dan monitoring pada ruang server dengan baik dan dapat mengontrol lampu secara otomatis.

Hasil pengujian dapat diketahui bahwa sensor DHT11 dapat mendeteksi suhu bernilai tinggi dan kelembaban bernilai rendah apabila sensor didekatkan dengan solder, suhu bernilai rendah dan kelembaban bernilai tinggi apabila diletakkan diruang berAC. Selanjutnya pada Sensor PIR, sensor dapat mendeteksi pergerakan manusia di dalam ruang server dibawah jarak $670 \mathrm{~cm}$, apabila ada pergerakan manusia jaraknya diatas $670 \mathrm{~cm}$ maka sensor tidak dapat mendeteksi pergerakan. Begitu juga dengan IR Transmitter, IR Transmitter akan berhasil mengirimkan data dengan jarak dibawah $480 \mathrm{~cm}$ dalam penelitian yaitu pengiriman perintah dari mikrokontroler ke AC untuk pengontrolan suhu ruang server. Apabila jarak alat dengan AC diatas $480 \mathrm{~cm}$ maka AC tidak dapat menerima perintah dari sistem. Pada pengujian mikrokontroler didapatkan hasil tampilan pada LCD sebagai berikut : LCD menampilkan tulisan wifi terhubung ketika mikrokontroler NodeMCU terkoneksi ke wifi, apabila tidak terkoneksi LCD akan menampilkan tulisan wifi menghubungkan. LCD menampilkan tulisan MQTT terhubung ketika mikrokontroler NodeMCU terkoneksi ke server MQTT, apabila tidak terkoneksi LCD akan menampilkan tulisan MQTT menghubungkan. LCD menampilkan tulisan perbaruhi temperature optimal apabila mikrokontroler NodeMCU mendapatkan nilai temperature optimal dari sistem web. LCD akan menampilkan tulisan berhasil mengirim data apabila mikrokontroler berhasil mengirimkan data suhu dan kelembapan ke database, jika gagal LCD menampilkan tulisan gagal mengirim data.

\section{SIMPULAN}

Berdasarkan penelitian dan pembahasan implementasi sistem sengaturan suhu ruang server menggunakan sensor DHT11 dan sensor PIR berbasis mikrokontroler dapat disimpulkan : (1) Sistem dapat mengontrol suhu ruangan dengan cara memberikan perintah kepada AC untuk menaikkan atau menurunkan suhu ruang server secara otomatis sesuai dengan suhu optimal yang telah ditentukan pada sistem ini, (2) Sistem dapat menampilkan data suhu dan kelembapan ke dalam website yang terkoneksi dengan jaringan internet, (3) Sistem dapat mengontrol lampu ruang server secara otomatis menyala ketika mendeteksi pergerakan manusia dan akan mati ketika tidak ada pergerakan.

\section{REFERENSI}

Abdullah, R. R., \& Wibowo, A. (2014). Monitoring Suhu Ruangan Server Dengan Fuzzy Logic Metode Sugeno Menggunakan Arduino Dan SMS. SWABUMI, 1(1), 1-9.

Aryandhi, Y. D., \& Talakua, M. W. (2013). Penerapan Inferensi Fuzzy Untuk Pengendali Suhu Ruangan Secara Otomatis Pada Air Conditioner (AC). Prosiding FMIPA Universitas Pattimura 2013 (pp. 177-185). Indonesia: FMIPA Universitas Pattimura.

Djaeng, D. S., \& Astutik, D. (2017). Rancang Bangun Lampu Otomatis Dengan Sensor Passive Infra Red ( PIR ) Berbasis Raspberry Pi. Jurnal Elektronik Sistem Informasi Dan Komputer, 3(2), 48-58.

Fauzi, M. R., \& Mukhtar, H. (2016). Rancang Bangun Sistem Pengaturan Temperatur Ruangan Menggunakan Sensor DHT11 Berbasis Mikrokontroler Arduino. PROSIDING 1th Celscitech-UMRI (pp. 122-126). Indonesia: LP2M-UMRI. 
Iqbal, M., Yulkifli, \& Darvina, Y. (2019). Rancang Bangun Sistem Pengukuran Suhu Dan Kelembaban Udara Menggunakan Sensor SHT75 Berbasis Internet of Things Dengan Display Smartphone. Berkala Fisika, 22(3), 97-104.

Khoswanto, H., Pasila, F., \& Cahyadi, W. E. (2003). Sistem Pengaturan AC Otomatis. Jurusan Teknik Elektro, Fakultas Teknologi Industri, 3(2), 73-78.

Lukman, M. P., . J., \& Rieuwpassa, Y. F. Y. (2018). Sistem Lampu Otomatis Dengan Sensor Gerak, Sensor Suhu Dan Sensor Suara Berbasis Mikrokontroler. Jurnal Rekayasa Sistem Komputer, 1(2), 100-108.

Mulyono, S., \& Haviana, S. F. C. (2018). Implementasi MQTT untuk Pemantauan Suhu dan Kelembaban pada Laboratorium. Jurnal Transistor Elektro Dan Informatika, 3(3), 140144.

Partamayasa, I. W. G., Suhartana, I. K. G., \& Supriana, I. W. (2019). Perancangan Sistem Pengaturan Suhu Ruangan Otomatis Berbasis Mikrokontroler. Jurnal Elektronik Ilmu Komputer Udayana, 8(1), 95-104.

Periyaldi, P., Bramanto, A., \& Wajiansyah, A. (2018). Implementasi Sistem Monitoring Suhu Ruang Server Satnetcom Berbasis Internet Of Things (Iot) Menggunakan Protokol Komunikasi Message Queue Telemetry Transport (Mqtt). JTT (Jurnal Teknologi Terpadu), 6(1), 23-29.

Permana, E., \& Herawati, S. (2018). Rancang Bangun Sistem Monitoring Suhu Ruangan Bagian Pembukuan Berbasis Web Meggunakan Mikrokontroler Arduino Uno R3. Jurnal Teknologi Informasi Dan Komunikasi STMIK Subang, 1-16.

Prihatmoko, D. (2016). Perancangan Dan Implementasi Pengontrol Suhu Ruangan Berbasis Mikrokontroller Arduino Uno. Simetris: Jurnal Teknik Mesin, Elektro Dan Ilmu Komputer, 7(1), 117-122.

Siswanto, Gata, W., \& Tanjung, R. (2017). Kendali Ruang Server Menggunakan Sensor Suhu DHT 22, Gerak Pir dengan Notifikasi Email. Prosiding Seminar Nasional Sisfotek (pp. 134-142). Indonesia: Ikatan Ahli Informatika Indonesia (IAII).

Suherman, Andriyanto, I., \& Dwiyatno, S. (2015). Rancang Bangun Alat Ukur Temperatur Suhu Perangkat Server Menggunakan Sensor LM35 Bebasis SMS Gateway. Jurnal Prosisko, 2(1), 42-63.

Supriyanto, A. A., Kurnia, D., \& Hani, L. D. N. (2017). Monitoring Suhu Ruangan Berbasis Web. Elektra, 2(2), 10-19.

Wijanarko, D., \& Hasanah, S. (2017). Monitoring Suhu Dan Kelembaban Menggunakan SMS Gateway Pada Proses Fermentasi Tempe Secara Otomatis Berbasis Mikrokontroler. Jurnal Informatika Polinema, 4(1), 49-56.

Wijaya, R. A., Lestari, S. W., \& Mardiono, M. (2018). Rancang Bangun Alat Monitoring Suhu dan Kelembaban Pada Alat Baby Incubator Berbasis Internet Of Things. Jurnal Teknologi, 6(1), 52-70. 